\title{
Synthesis and characterization of vacancy-doped neodymium telluride for thermoelectric applications
}

Steven J. Gomez, ${ }^{1,2 \dagger}$ Dean Cheikh, ${ }^{\dagger}{ }^{\dagger}$ Trinh Vo, ${ }^{1}$ Paul Von Allmen, ${ }^{1}$ Kathleen Lee, ${ }^{1}$ Max Wood, ${ }^{3}$ G. Jeff Snyder, 3 Bruce S. Dunn, ${ }^{2}$ Jean-Pierre Fleurial, ${ }^{1}$ and Sabah K. Bux ${ }^{*}$

'Thermal Energy Conversion Technologies Research and Advancement Group, Jet Propulsion Laboratory, California Institute of Technology, 480o Oak Grove Drive, Pasadena, California 91109-8099

${ }^{2}$ Department of Materials Science and Engineering, University of California, Los Angeles 90092

3Department of Materials Science and Engineering, Northwestern University, Evanston, Illinois 60208

tThese authors contributed equally to this work.

\section{Supplemental Data}

Table S1: Sample porosities listed along with theoretical and measured densities of pressed $\mathrm{Nd}_{3-x} \mathrm{Te}_{4}$ samples. Theoretical densities were predicted using nominal compositions. Measurements were performed using the Archimedes method, showing densities above $96 \%$ of theoretical values. The nominal $\mathrm{Nd}_{2.72} \mathrm{Te}_{4}$ sample shows a high amount of porosity (5\%) mainly from pullout during polishing, a result of the sample being mechanically weak.

\begin{tabular}{c|c|c|c}
$\begin{array}{c}\text { Nominal } \\
\text { Composition }\end{array}$ & $\begin{array}{c}\text { Theoretical Density } \\
\left(\mathrm{g} \mathrm{cm}^{-3}\right)\end{array}$ & $\begin{array}{c}\text { Measured Density } \\
\left(\mathrm{g} \mathrm{cm}^{-3}\right)\end{array}$ & $\begin{array}{c}\text { Calculated } \\
\text { Porosity }\end{array}$ \\
\hline $\mathrm{Nd}_{3} \mathrm{Te}_{4}$ & 7.46 & 7.17 & $0.12 \%$ \\
$\mathrm{Nd}_{2.90} \mathrm{Te}_{4}$ & 7.34 & 7.27 & $0.086 \%$ \\
$\mathrm{Nd}_{2.86} \mathrm{Te}_{4}$ & 7.30 & 7.24 & $0.023 \%$ \\
$\mathrm{Nd}_{2.79} \mathrm{Te}_{4}$ & 7.23 & 7.22 & $0.033 \%$ \\
$\mathrm{Nd}_{2.74} \mathrm{Te}_{4}$ & 7.16 & 7.12 & $0.068 \%$ \\
$\mathrm{Nd}_{2.72} \mathrm{Te}_{4}$ & 7.14 & 7.08 & $4.977 \%$
\end{tabular}




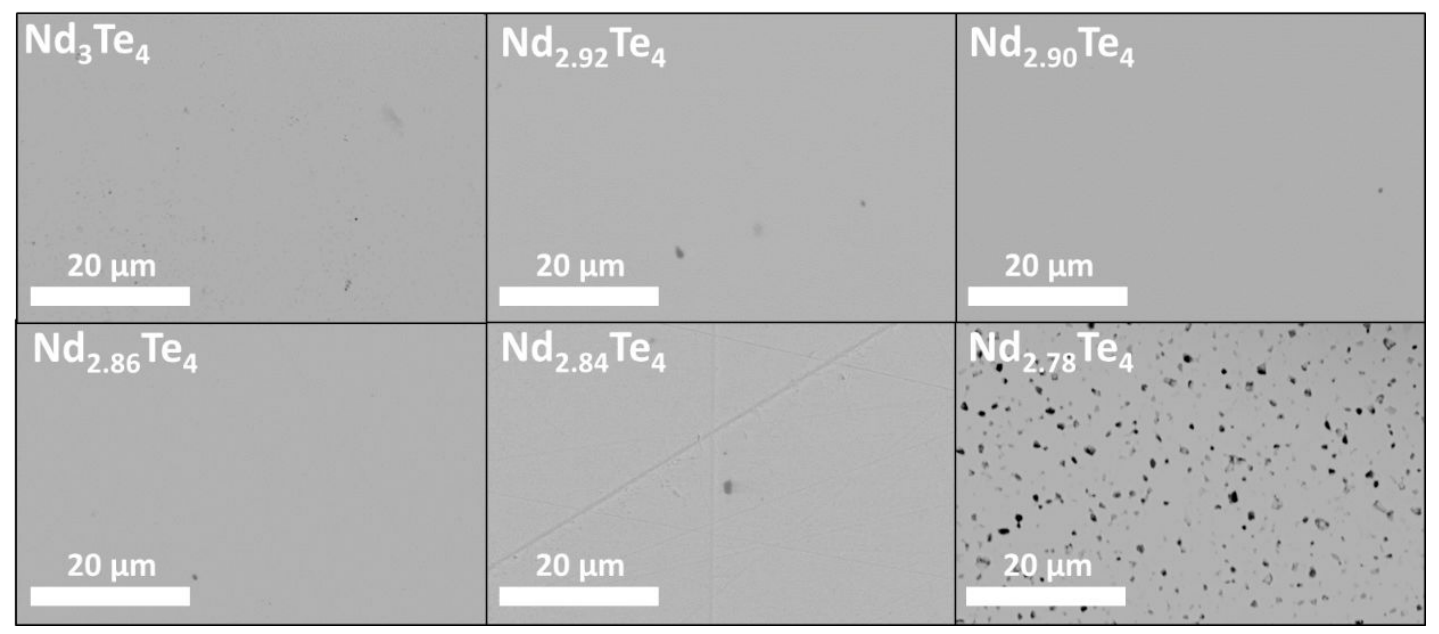

Figure S1: BSE SEM images (5000x) of $\mathrm{Nd}_{3-x} \mathrm{Te}_{4}$ at various vacancy concentrations. The uniformity of the image contrast reflects the homogeneity of the samples. Dark areas are indicative of sample porosity. Sample porosities for all samples except $\mathrm{Nd}_{2.78} \mathrm{Te}_{4}$ were less than $0.1 \%$, calculated using an area fraction of each SEM image. The $\mathrm{Nd}_{2.78} \mathrm{Te}_{4}$ sample shows a high amount of porosity (5\%) mainly from pullout during polishing, a result of the sample being mechanically weak. 


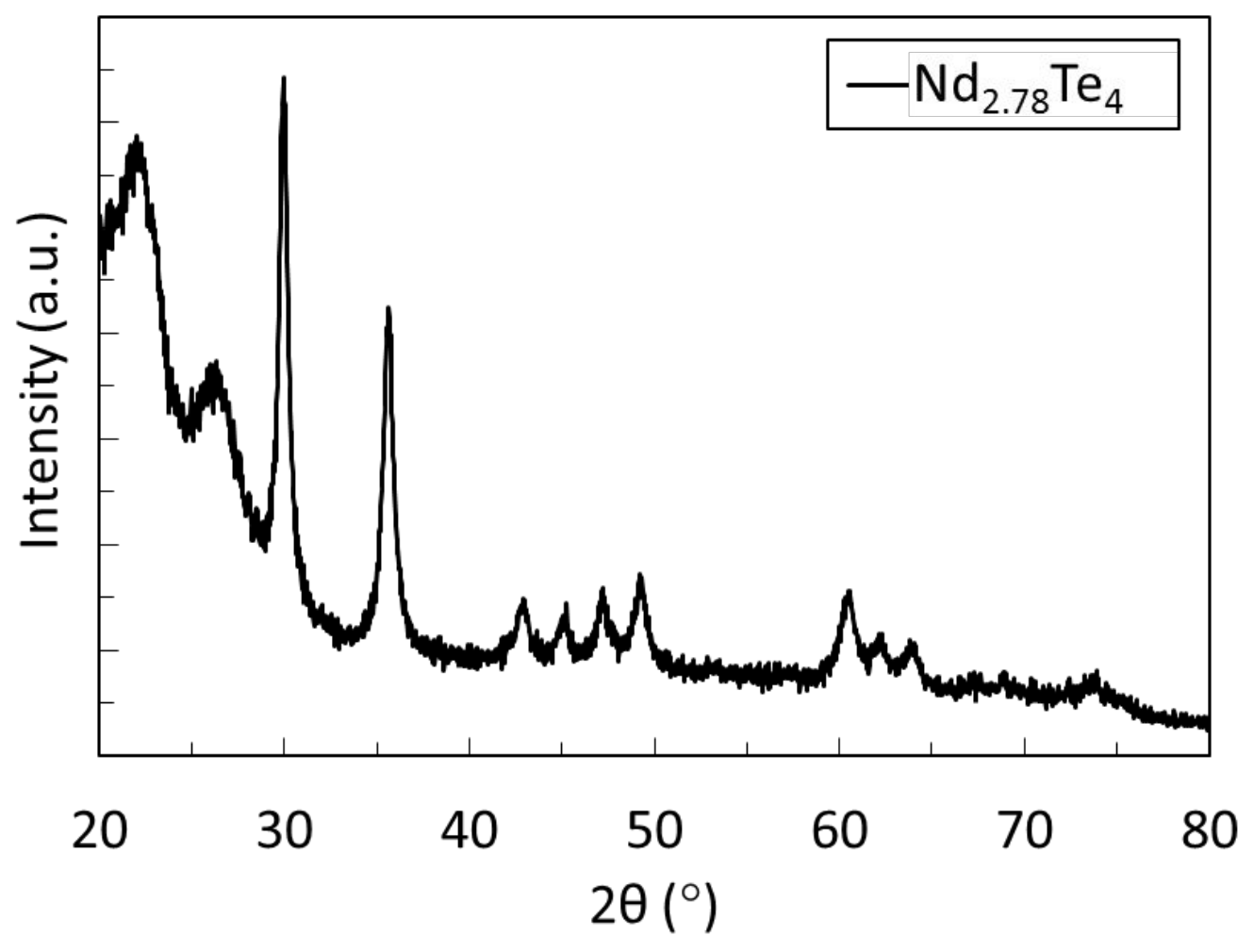

Figure S2: X-ray diffraction patterns for $\mathrm{Nd}_{3-x} \mathrm{Te}_{4}$ powder immediately after ball milling, confirming the $\mathrm{Th}_{3} \mathrm{P}_{4}$ structure type. Significant background for values of $2 \theta$ below $30^{\circ}$ is caused by a Kapton film in the sample holder. 


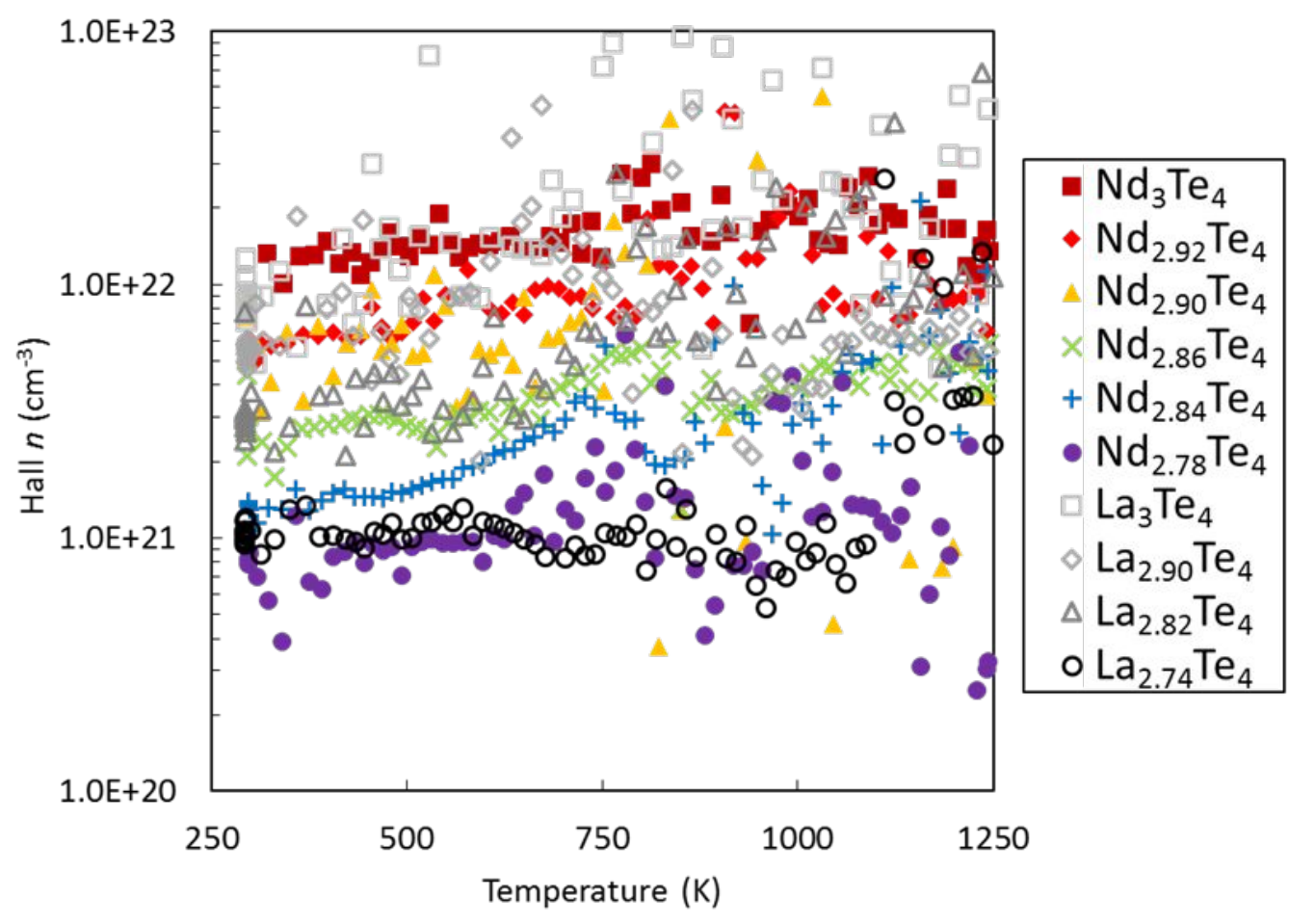

Figure S3: Temperature-dependent carrier concentration for $\mathrm{Nd}_{3-x} \mathrm{Te}_{4}$ samples compared to $\mathrm{La}_{3-x} \mathrm{Te}_{4}$. 


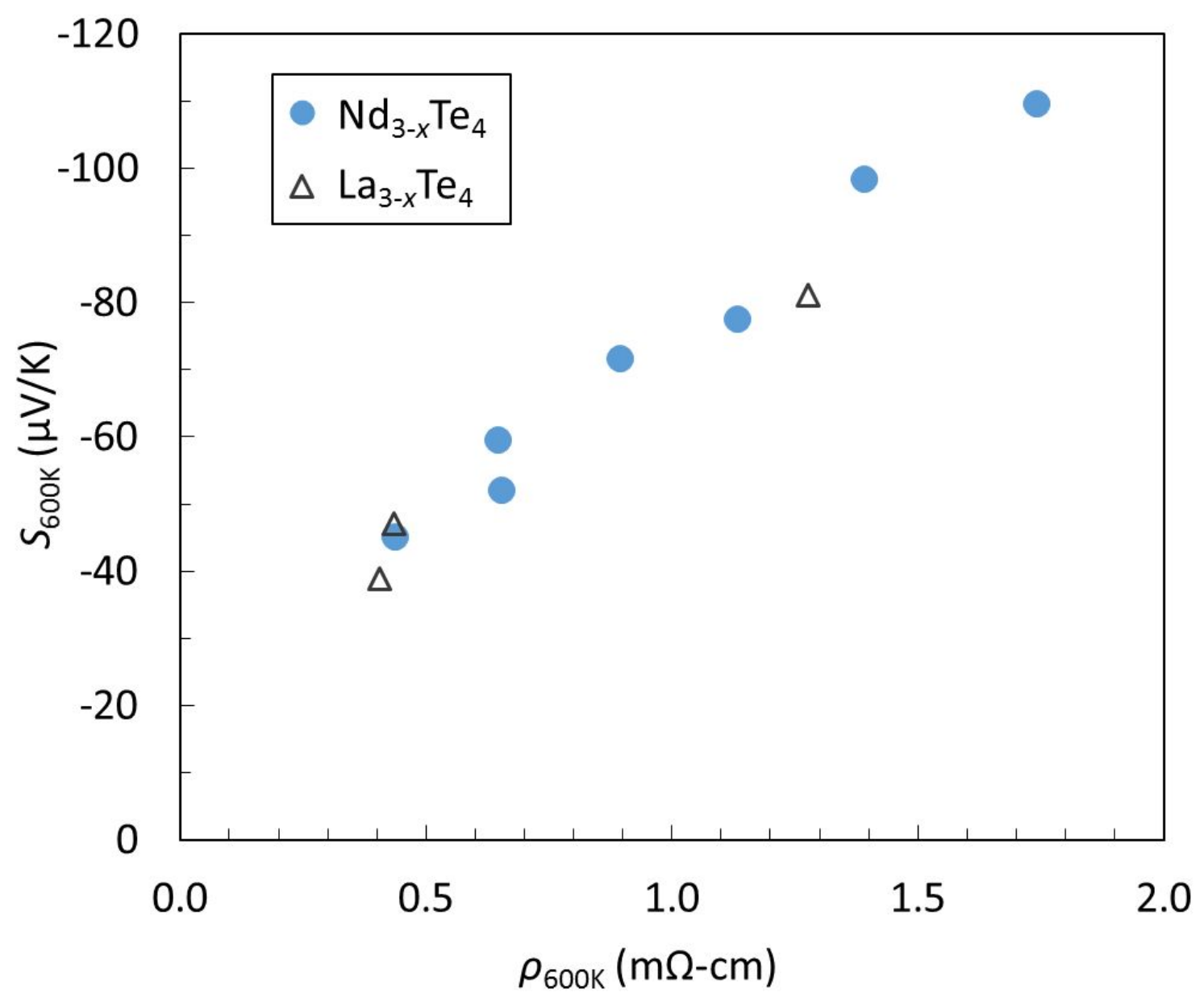

Figure S4: Plot of Seebeck vs. resistivity at $600 \mathrm{~K}$ for $\mathrm{Nd}_{3-x} \mathrm{Te}_{4}$ and $\mathrm{La}_{3-x} \mathrm{Te}_{4} \cdot{ }^{10}$ The simultaneous increase in Seebeck and resistivity agrees with the decrease in carrier concentration. 


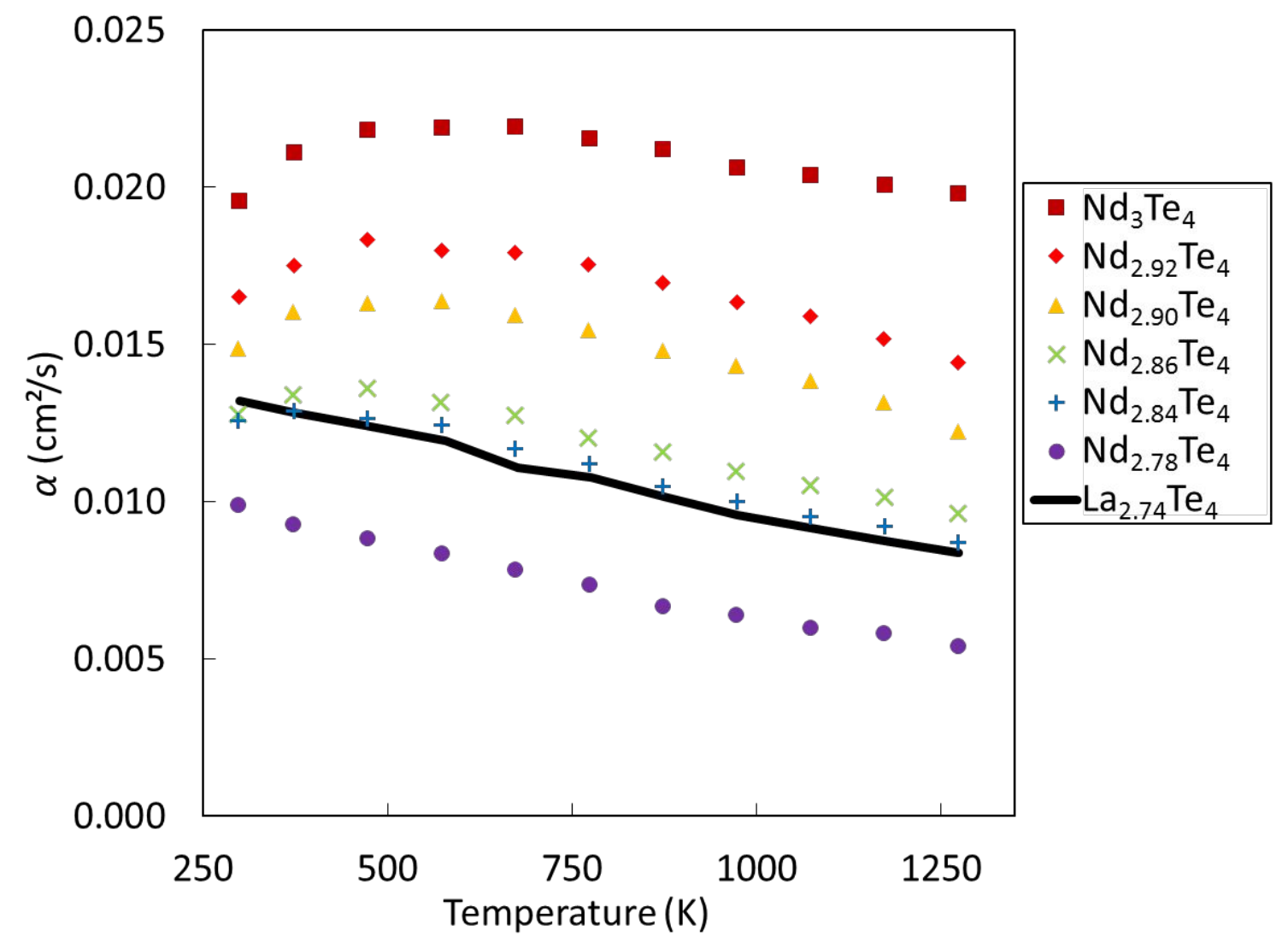

Figure S5: Temperature dependent thermal diffusivity of $\mathrm{Nd}_{3-x} \mathrm{Te}_{4}$ compared to that of $\mathrm{La}_{2.74} \mathrm{Te}_{4}$. 


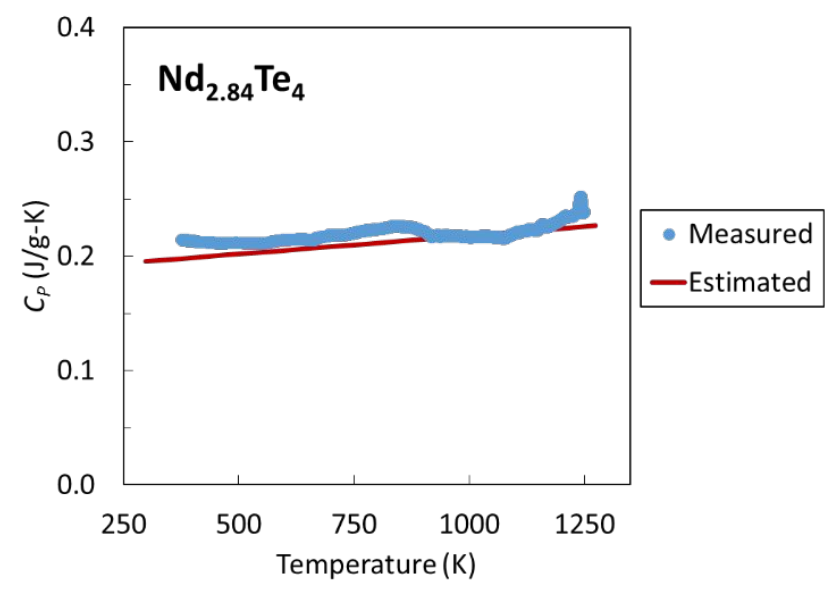

Figure S6: Measured temperature dependent heat capacity for $\mathrm{Nd}_{2.84} \mathrm{Te}_{4}$, compared against values estimated by multiplying the heat capacity of $\mathrm{La}_{3} \mathrm{Te}_{4}$ by the ratio of the molecular weights. Both samples show excellent agreement between estimated and measured values. 


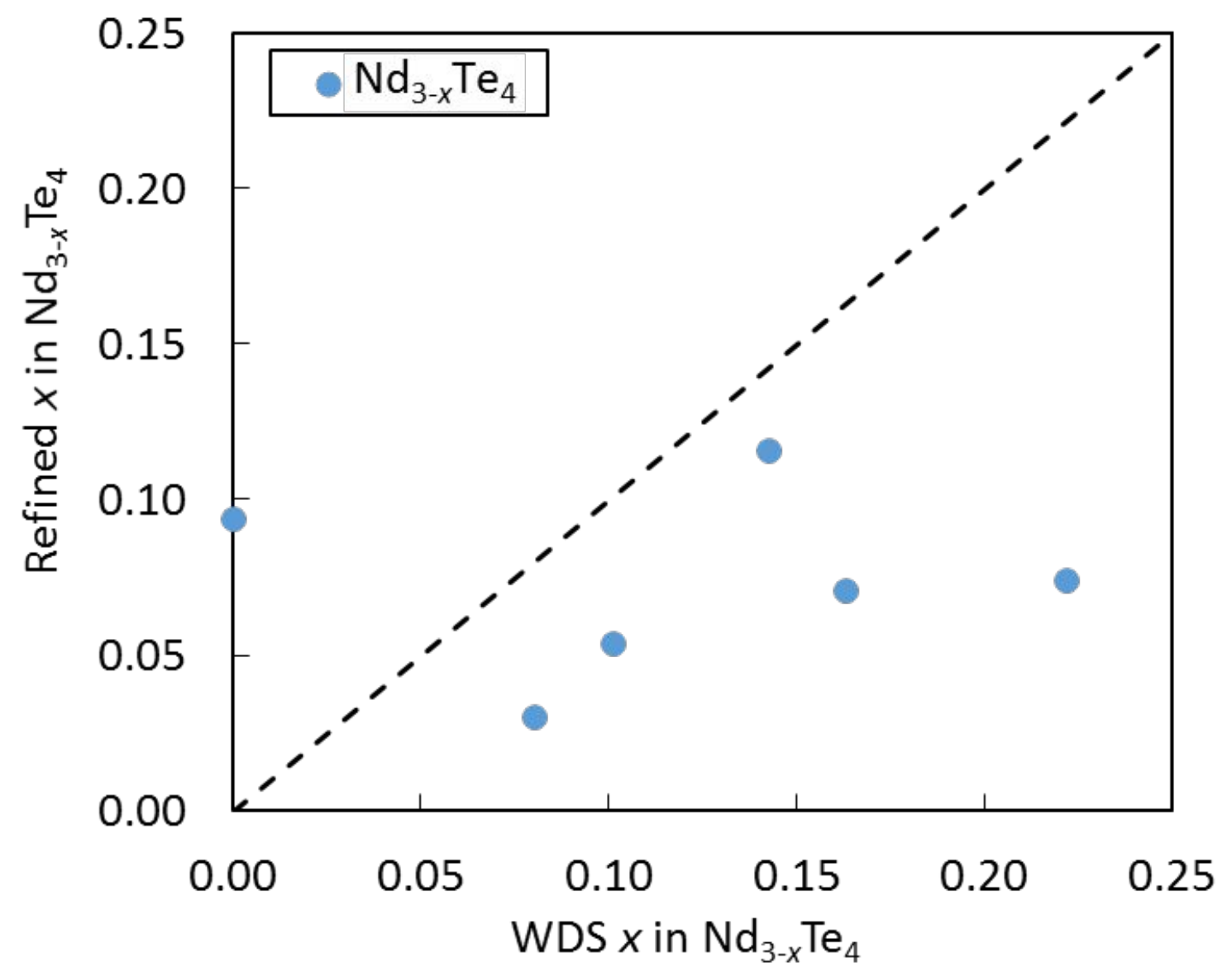

Figure S7: Refined $x$ in $\mathrm{Nd}_{3-x} \mathrm{Te}_{4}$ obtained by Rietveld refinement versus measured $x$ obtained by WDS. 


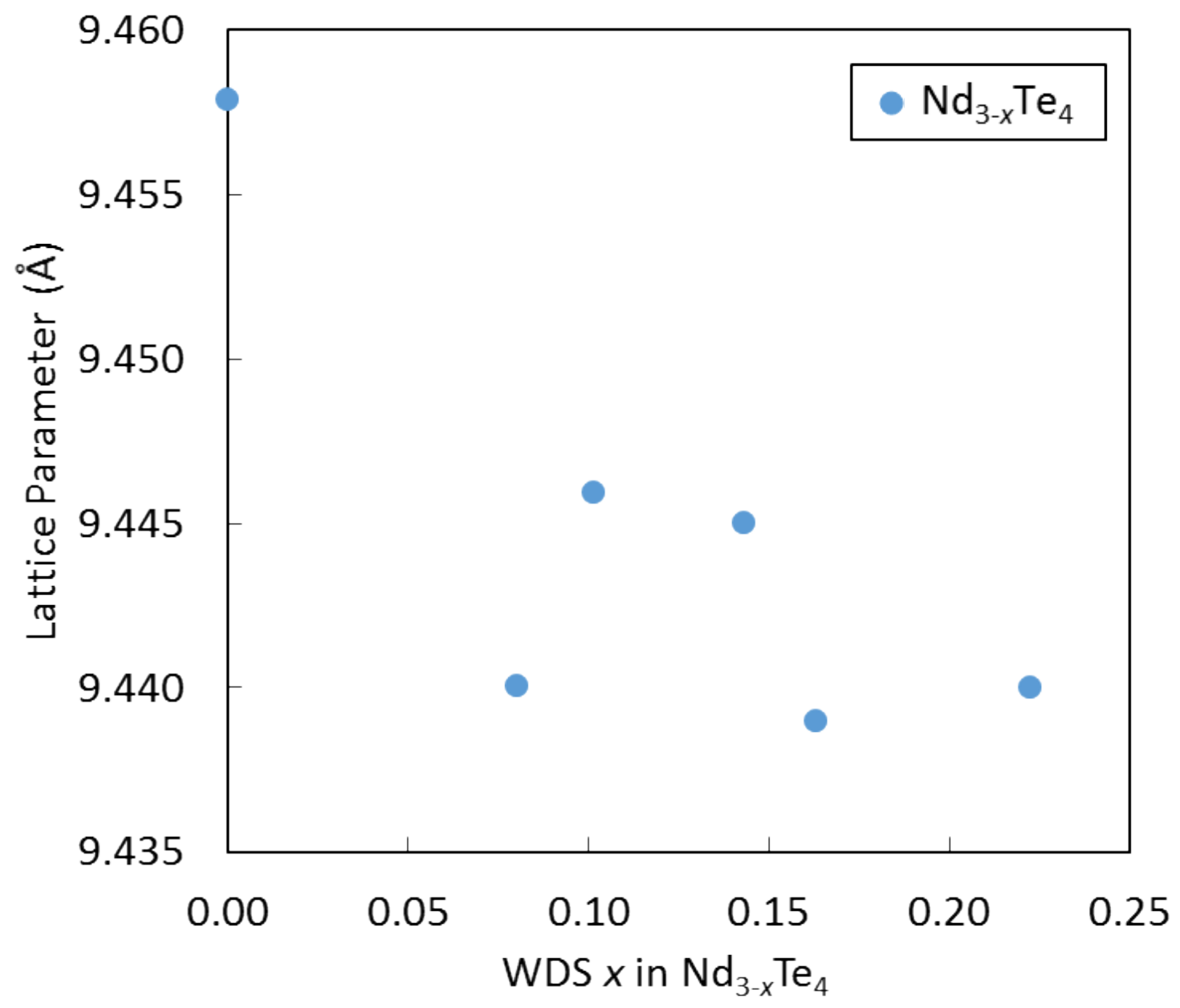

Figure S10: Refined lattice parameter obtained by Rietveld refinement as a function of measured $x$ in $\mathrm{Nd}_{3-x} \mathrm{Te}_{4}$ obtained by WDS. These are in good agreement with the published value of $9.435 \AA .{ }^{26}$ 


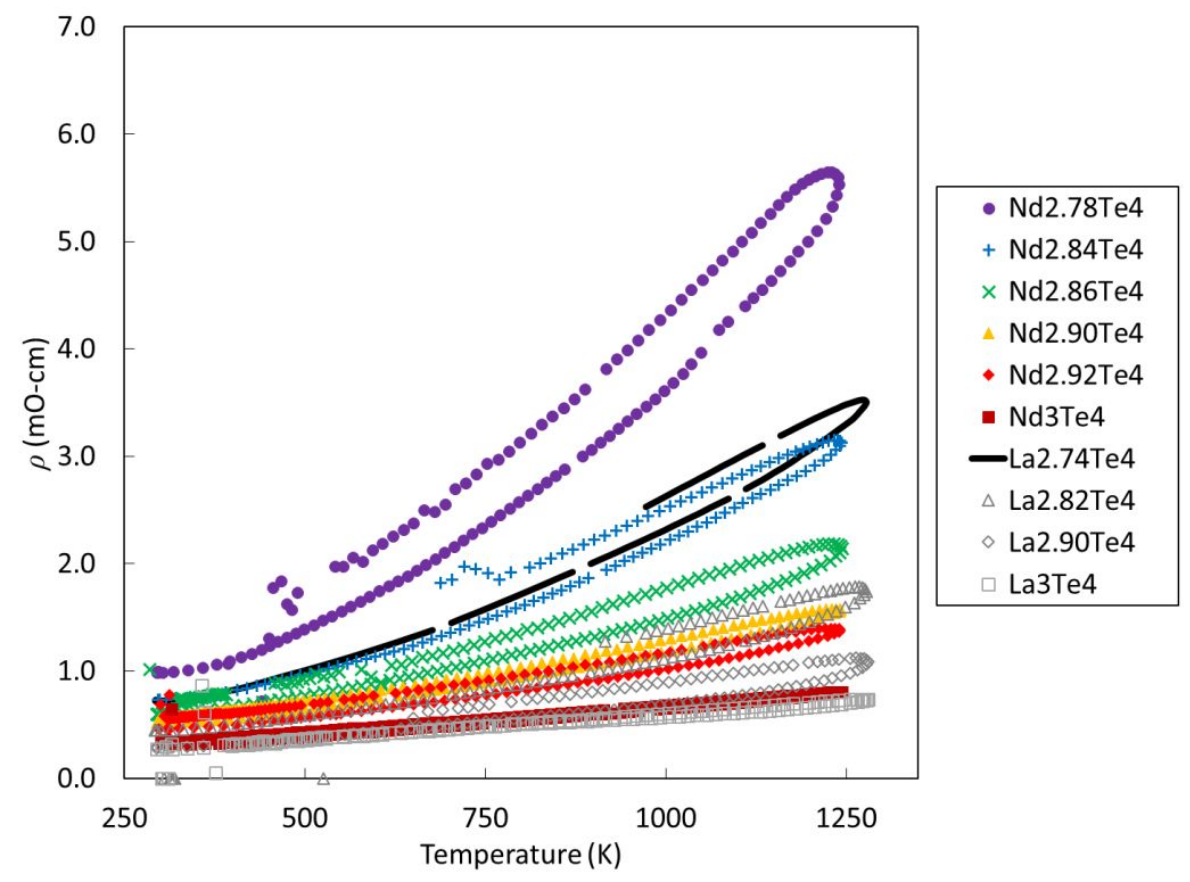

Figure S11: Heating and cooling cycles for temperature-dependent resistivity measurements showing only small hysteresis. 


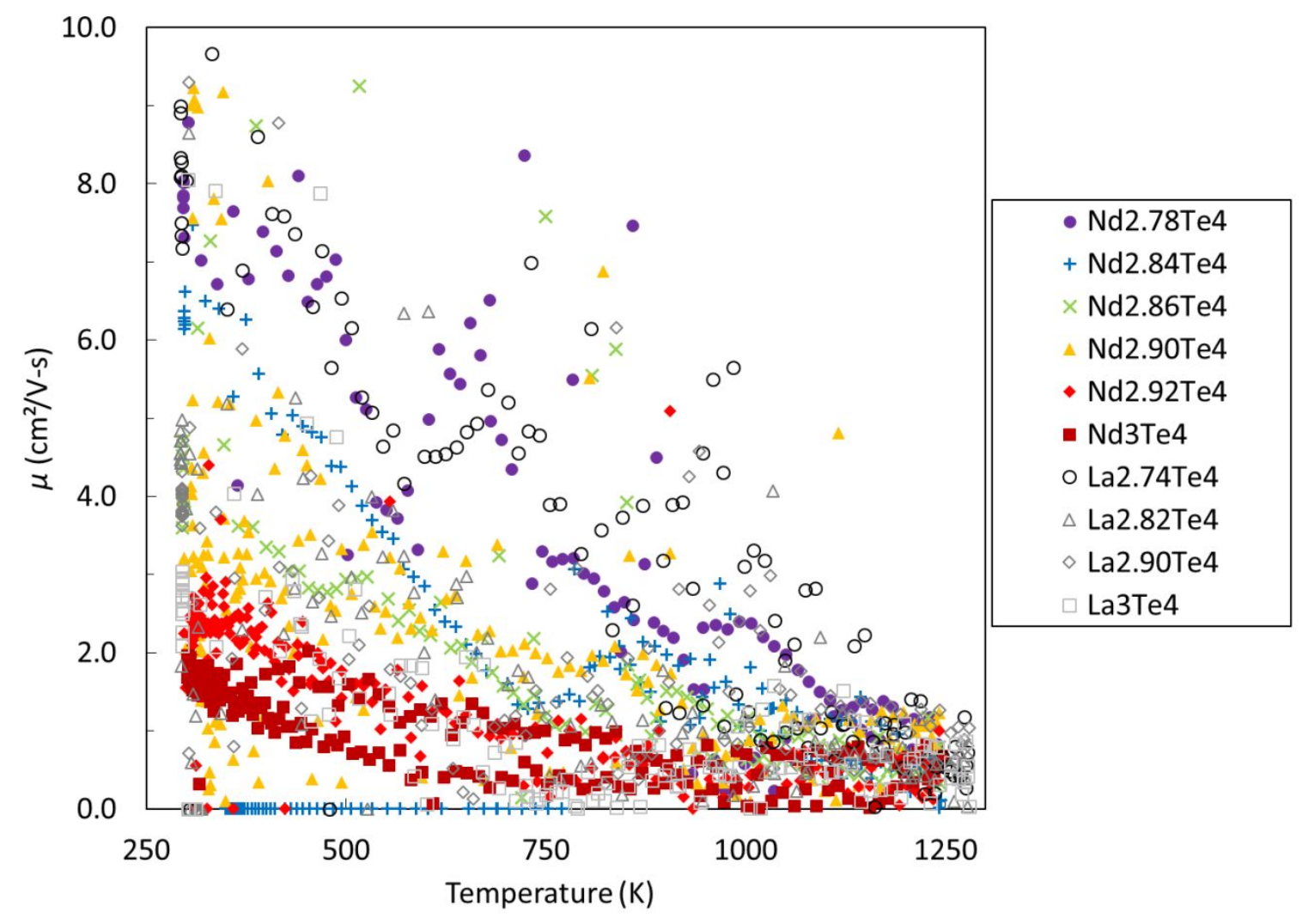

Figure S12: Heating and cooling cycles for temperature-dependent mobility measurements. 


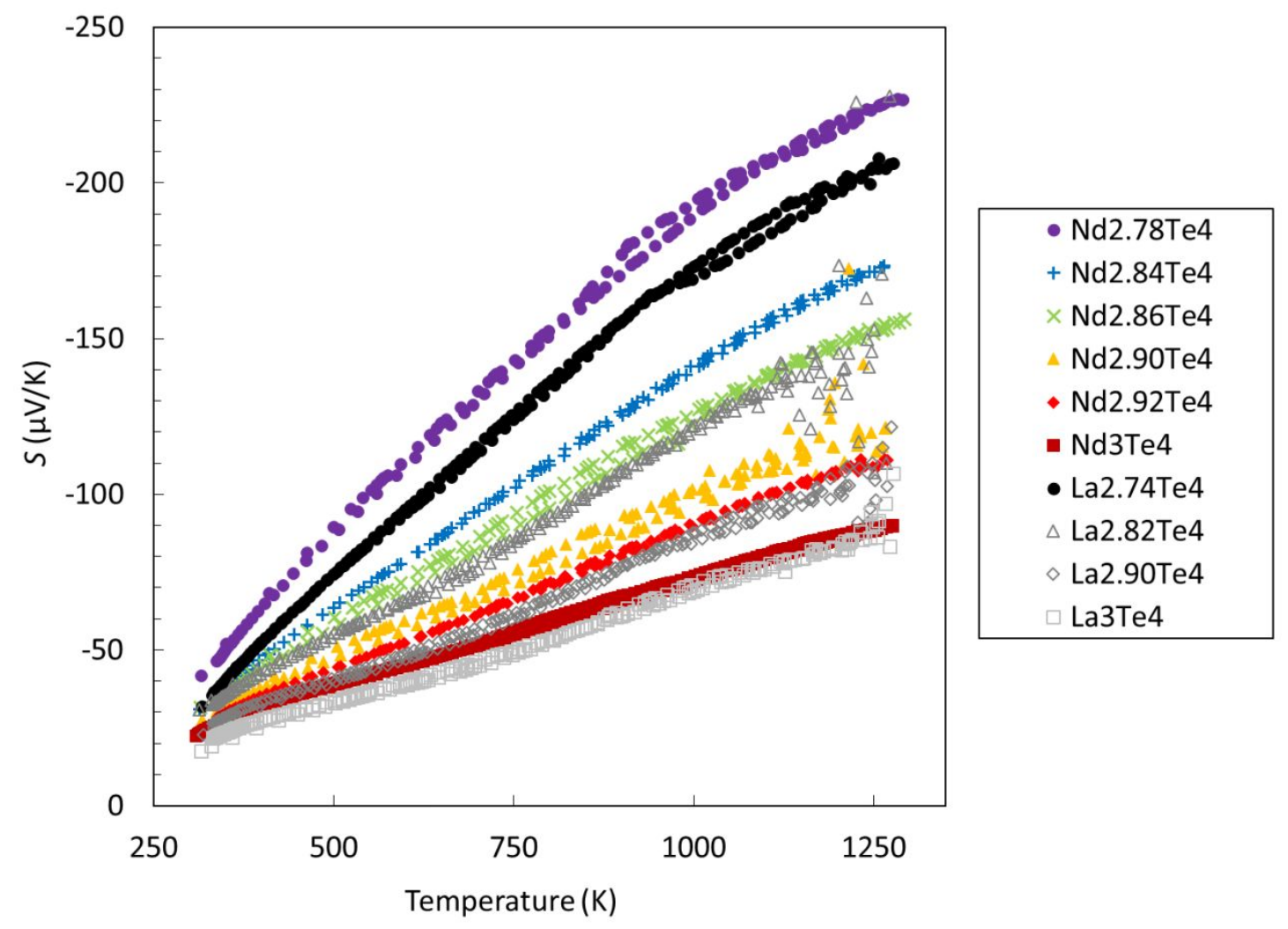

Figure S13: Heating and cooling cycles for temperature-dependent Seebeck coefficient measurements showing excellent agreement between heating and cooling data. 